\title{
Wheat Leaf Rust Uredospore Production and Carbon and Nitrogen Export in Relation to Lesion Size and Density
}

\author{
Corinne Robert, Marie-Odile Bancal, and Christian Lannou
}

First and second authors: INRA Environnement et Grandes Cultures, BP 01, 78850 Thiverval Grignon, France; and third author: INRA

Pathologie Végétale, BP 01, 78850 Thiverval Grignon, France.

Accepted for publication 12 March 2002.

\begin{abstract}
Robert, C., Bancal, M.-O., and Lannou, C. 2002. Wheat leaf rust uredospore production and carbon and nitrogen export in relation to lesion size and density. Phytopathology 92:762-768.

To develop mechanistic yield loss models for biotrophic fungi, we need better account for the export of dry matter, carbon, and nitrogen from the leaf into the spores. Three experiments in controlled environment chambers were performed to study the dynamics of uredospores production of Puccinia triticina on seedling leaves of wheat in relation to

strongly decreased. However, our results showed that increasing lesion density also greatly reduces lesion size. A model was developed to summarize these relationships. Our main conclusion is that the density effect on spore production per lesion is accounted for by lesion size. When sporulation was related to the sporulating surface area, it became independent of density. As well, carbon and nitrogen contents of the spores were independent of lesion density. Our data suggest that when nitrogen available in the host is limiting, spore production is reduced but nitrogen content of spores tend to remain stable.
\end{abstract} time, lesion density, and sporulating surface area. The detrimental effect of lesion density on the sporulation capacity of brown rust lesions was confirmed. When lesion density increased, spores production per lesion
Additional keywords: brown rust, Triticum aestivum, yield reduction.
The development of integrated pest management systems requires mechanistic models that can simulate the effect of disease on yield. These models must be firmly rooted in a clear understanding of the biological mechanisms involved. Such models require quantitative information on the effects of a disease on physiological processes. In the case of leaf rust caused by Puccinia triticina of wheat (Triticum aestivum), the effects of the disease on photosynthesis, respiration, and foliar transpiration have been documented $(7,17)$. However, for brown rust as well as for many other biotrophic fungi, spore production results in a significant loss of biomass by the diseased crop that is rarely taken into account in current models (19). Bastiaans (3) quantified the effect of rice leaf blast (caused by Magnaporthe grisea) on leaf photosynthesis and respiration in order to model the consequences of the disease on rice dry matter production. He found that the changes in photosynthesis and respiration were insufficient to fully explain the observed reduction in shoot dry weight, and suggested that the dry matter exported in the spores, which was neglected in the model, accounted for the overestimated diseased shoot dry weight in the simulations. For leaf rusts, Van Roermund and Spitters (19) also considered the uptake of assimilates for spore production as a cause of damage. Their field studies indicated that leaf rusts could consume up to 230 to $570 \mathrm{~kg}$ of $\mathrm{CH}_{2} \mathrm{O}$ per ha for spore production. Therefore, any model designed to describe the effect of brown rust on crop growth and yield must accurately describe the loss of dry matter resulting from spore production. Spore production must also be quantified throughout the lifetime of a rust lesion, because damage depends greatly on the crop growth stage (11).

Other authors have described brown rust spore production per lesion at different disease severities $(13,14)$. Spore production per

Corresponding author: C. Robert; E-mail address: robert@ bcgn.grignon.inra.fr

Publication no. P-2002-0520-01R

(c) 2002 The American Phytopathological Society lesion increases to a maximum and then gradually decreases to zero, so that the shape of the spore production curve is an asymmetrical bell-shaped curve. Density greatly affects the sporulation capacity of brown rust lesions (14). When lesion density increases, spore production per lesion strongly decreases and reaches its maximum value faster. In these studies, spore production was quantified as the number of spores per lesion, rather than by the export of dry matter. The latter parameter is needed, however, to relate spore production to damage resulting in crop loss. These studies also linked spore production to lesion density (number of lesions per leaf), whereas damage-analysis models usually consider diseased area as an impact variable $(2,6,10$, 12,16). For instance, Shtienberg (17) worked on brown rust and showed that the decrease in photosynthesis is proportional to the diseased leaf area. The present study was to estimate the export of dry matter into spores and to relate spore production to the sporulating area at different lesion densities. We also measured the export of carbon and nitrogen into the spores in relation to lesion density.

\section{MATERIALS AND METHODS}

Seedlings of wheat cv. Soissons were grown in commercial compost (peat substrate, Gebr. Brill Substrate; GmbH \& Co., Germany) in square pots $(7 \times 7 \mathrm{~cm}$, eight seedlings per pot) in a growth chamber with a 16-h light period $\left(250 \mu \mathrm{E} \mathrm{m}^{-2} \mathrm{~s}^{-1}\right)$ at $18^{\circ} \mathrm{C}$ and an 8-h dark period at $15^{\circ} \mathrm{C}$. Isolate B9384-1C1 of $P$. triticina was used in all experiments. The primary leaves of seedlings were inoculated in a settling tower (5) 10 days after sowing, before the emergence of the second leaf. Different lesion densities were obtained by inoculating the seedlings with a mixture of brown rust spores and talc in which the spore contents were 6, 3, 1.5, 0.75, and $0.375 \mathrm{mg}$. Inoculated plants were incubated for $16 \mathrm{~h}$ under $100 \%$ relative humidity in plastic bags at $15^{\circ} \mathrm{C}$ and placed in a growth chamber until the end of the experiment. When chlorosis was visible, two inoculated leaves per pot were selected according 
to lesion density. Spore production was estimated by collecting and weighing spores for each inoculated leaf at regular intervals after onset of sporulation as described below. The experiment was repeated three times (experiments 1, 2, and 3). Spore production was modeled as a function of time and lesion density using the data of experiment 1 (32 leaves). Data of experiment 2 were used to validate the spore production model (10 leaves) and to model changes in lesion size with time and lesion density (22 leaves). Spore production was not assessed on these 22 leaves because, when shooting the leaves with camera for lesion size measurement, spores would have been lost. Although the experimental design was the same for all experiments, the appearance of the leaves in experiment 3 (27 leaves) suggested that seed germination and first leaf development were not optimal. The reason for this was probably asphyxiation of the roots due to overwatering. Experiment 3 was therefore not used to estimate parameters.

Lesion density. The number of lesions per leaf was counted twice, 8 and 10 days after inoculation. Lesions started to sporulate 9 days after inoculation. Leaves were then selected so lesion densities were 0.1 to 40 lesions per $\mathrm{cm}^{2}$ of leaf. No secondary infection occurred during the experiment and the lesion number was considered constant after day 10 . However, rings of secondary lesions appeared around very low-density primary lesions about 1 week after onset of sporulation. Leaf area $(S$, in square centimeters) was estimated by linear regression from leaf length ( $L$, in centimeters) on 40 primary leaves grown as described previously $\left(S=0.44 \times L-0.12, R^{2}=0.92, P<10^{-4}\right)$. The length of each leaf was measured and lesion density was calculated by dividing the number of lesions by the estimated leaf area $(S)$.

Spore collection. Spores were collected every 2 or 3 days from day 3 after initial sporulation until the end of sporulation. Before onset of sporulation, leaves were placed horizontally in $3-\mathrm{cm}-$ diameter glass tubes. Plants were placed on a turntable in the growth chamber to ensure uniform light and temperature. This caused the air to flow into the tubes and prevented water condensation. Spores were collected by shaking the leaves so that the spores fell onto the glass tubes, from which they were collected and weighed. The tubes were replaced until the next collection. Secondary leaves were cut off after each spore collection.

Spore production model. The data from experiment 1 , obtained from 32 infected leaves, were used to model spore production. The relationship between cumulative spore production per lesion $(Y$, in milligrams), lesion age ( $t=$ number of days after onset of sporulation, with $t=1$ for the first sporulation day) and lesion density ( $d=$ number of lesions per square centimeter of leaf) was established in a two-step procedure. Cumulative spore production per lesion at each collection date $(t)$ was first related to lesion density $(d)$ :

$$
\ln \left[Y_{t}(d)\right]=a_{t}-b_{t} \times \ln (d)
$$

Then, parameters $a(t)$ and $b(t)$ were related to lesion age $(t)$ by

$$
\begin{aligned}
& a(t)=m_{a}-\exp \left(c_{a}-f_{a} \times t\right) \\
& b(t)=m_{b}-\exp \left(c_{b}-f_{b} \times t\right)
\end{aligned}
$$

where $m_{a}$ and $m_{b}$ are the asymptotic values of $a(t)$ and $b(t)$, respectively, when $t \rightarrow \propto$. Parameters $m_{a}$ and $m_{b}$ were estimated by the maximum values, respectively, of $a(t)$ and $b(t)$ corresponding to the last collection date $(t=27)$. Parameters $c_{a}, f_{a}, c_{b}$, and $f_{b}$ were estimated after linearization of equation 2

$$
\begin{aligned}
& \ln [a(t)-a(27)]=c_{a}-f_{a} \times t \\
& \ln [b(t)-b(27)]=c_{b}-f_{b} \times t
\end{aligned}
$$

Combining equation 2 with equation 1 gave an estimate of the cumulative spore production per lesion at day $t$ after onset of sporulation for a lesion density $(d)$ :

$$
Y(t, d)=\exp \left\{m_{a}-\exp \left(c_{a}-f_{a} \times t\right)-\left[m_{b}-\exp \left(c_{b}-f_{b} \times t\right)\right] \times \ln (d)\right\}
$$

From day 4 of sporulation, daily spore production $(P$, in milligrams) per lesion for lesion age $(t)$ and lesion density $(d)$ was estimated by

$$
P(t, d)=Y(t, d)-Y(t-1, d)
$$

This model was validated with data obtained from 10 infected leaves in experiment 2. Spore production between $t=0$ and 3 was assumed to increase linearly for any density $d$, according to Sache (14).

Lesion size. In experiment 2, lesion size was measured on 22 leaves. We did not measure spore production on these leaves. Lesion size was defined as the lesion sporulating surface area. Digital pictures were taken at each spore collection date until 18 days after start of sporulation to accurately estimate the sporulating area by image analysis (Optimas, Media Cybernetics, Silver Spring, MD). Tissue senescence after day 18 made it more difficult to assess sporulating area, but lesion size could be considered constant after this date.

Lesion growth model. Lesion growth was modeled using the same procedure as spore production. For homogeneity with the spore production model, only data from days 4 to 18 were used to estimate parameters, although lesion size was measured from day 1 . Lesion size was assumed to increase linearly with time before day 4 . The relationship between lesion size $(S$, square millimeter of sporulating area), lesion age ( $t$, number of days after onset of sporulation), and lesion density $(d)$ was established in a two-step procedure. First, sporulating area was related to lesion density, $d$, at each date $t$ by

$$
\ln \left[S_{t}(d)\right]=u_{t}-v_{t} \times \ln (d)
$$

The estimated values of $u(t)$ and $v(t)$ were plotted against lesion age, $t$, and the following equations were fitted to the data for days $4,6,8,11,14$, and 18:

$$
\begin{aligned}
& u(t)=m_{u}-\exp \left(d_{u}-e_{u} \times t\right) \\
& v(t)=m_{v}-\exp \left(d_{v}-e_{v} \times t\right)
\end{aligned}
$$

where $m_{u}$ and $m_{v}$ are the asymptotic values of $u(t)$ and $v(t)$, respectively, when $t \rightarrow \propto$. Parameters $m_{u}$ and $m_{v}$ were estimated by the maximum of $u(t)$ and $v(t)$, respectively, corresponding to the last assessment date $(t=18)$. Parameters $d_{u}, e_{u}, d_{v}$, and $e_{v}$ were estimated by regression after linearizing equation 7 .

Combining equation 7 with equation 6 provided an estimate of the sporulating area of individual lesion $t$ days after onset of sporulation for a lesion density $(d)$ :

$$
S(t, d)=\exp \left\{m_{u}-\exp \left(d_{u}-e_{u} \times t\right)-\left[m_{v}-\exp \left(d_{v}-e_{v} \times t\right)\right] \times \ln (d)\right\}
$$

Nitrogen and carbon contents of leaves and uredospores. To estimate the export of nitrogen and carbon into uredospores, the nitrogen and carbon contents of the spores produced by each infected leaf were measured at the end of experiments 1,2 , and 3 . To characterize the initial status of the leaves and to estimate whether the nitrogen content of the leaves affects spore production, we measured the $\mathrm{N}$ and $\mathrm{C}$ levels in the primary leaves of check plants the day before inoculation for experiments 1 and 3 . The $\mathrm{C}$ and $\mathrm{N}$ contents of both spores and primary leaves were measured by the method of Dumas (4). 


\section{RESULTS}

Uredospore production. About $90 \%$ of the lesions on infected leaves started to sporulate 10 days after inoculation. This was considered to be the first sporulation day $(t=1)$. In experiments 1 and 2 , overall spore production per square centimeter of leaf (Fig. 1) increased with lesion density from $0.7 \mathrm{mg} / \mathrm{cm}^{2}$ of leaf for a lesion density of 1.5 lesions per $\mathrm{cm}^{2}$ to a maximum of around $4.5 \mathrm{mg} / \mathrm{cm}^{2}$ of leaf for lesion densities greater than 15 lesions per $\mathrm{cm}^{2}$. Uredospore production per square centimeter of leaf was more than $70 \%$ lower in experiment 3 than in experiment 1 for all lesion densities, and the maximum spore production was around $1 \mathrm{mg} / \mathrm{cm}^{2}$ of leaf at a lesion density greater than 15 lesions per $\mathrm{cm}^{2}$.

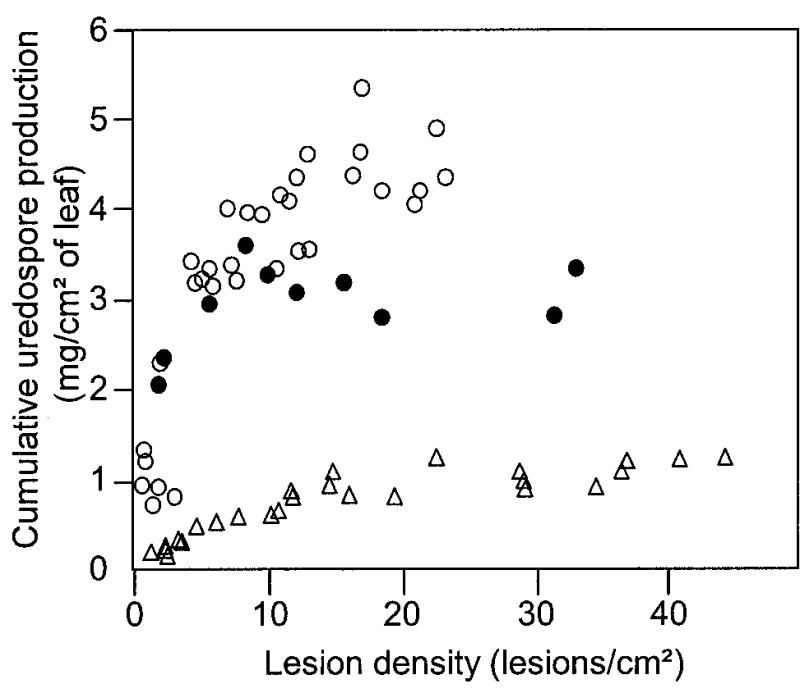

Fig. 1. Amount of spores produced by leaf rust (Puccinia triticina) on a primary leaf of susceptible wheat (cv. Soissons) against lesion density (lesions per square centimeter). Spore production is expressed in milligrams of spores (fresh weight) per square centimeter of leaf. Three sets of data are presented: experiment $1(O)$, experiment $2(\bullet)$, and experiment $3(\Delta)$. In experiment 3 , the nitrogen content of the leaves was limiting.
Cumulative uredospore production per lesion. Cumulative spore production per lesion was higher at lower lesion densities from day 6 after start of sporulation in experiments 1 and 2, and this density effect on spore production increased with time (Fig. 2). Cumulative spore production per lesion at the end of the sporulation period $(t=27)$ was around $1.5 \mathrm{mg}$ per lesion for the lowest lesion densities $\left(<1\right.$ lesion per $\left.\mathrm{cm}^{2}\right)$ and $0.10 \mathrm{mg}$ per lesion for the highest lesion densities $\left(>20\right.$ lesions per $\left.\mathrm{cm}^{2}\right)$. There was little density effect in experiment 3 .

Daily uredospore production per lesion. Spore production per lesion was measured every 3 days. Hence, daily spore production was estimated by dividing the amount of spores collected by the number of days between two successive collection dates. Spore

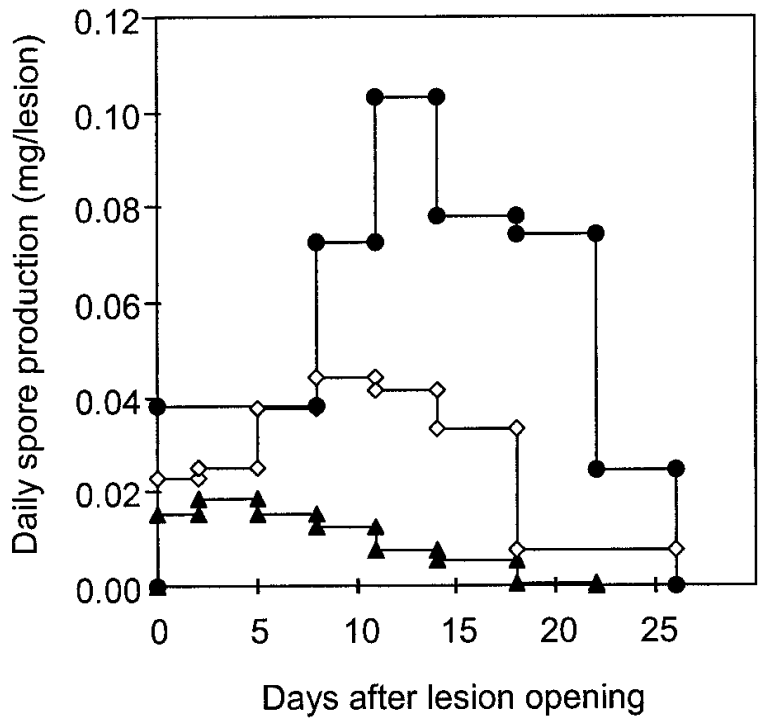

Fig. 3. Daily spore production per lesion for leaf rust (Puccinia triticina) on wheat (cv. Soissons), for different lesion densities $(\bullet=0.9$ lesion per square centimeter, $\diamond=4.6$ lesions per square centimeter, and $\boldsymbol{\Delta}=22.8$ lesions per square centimeter) as a function of time, in days after onset of sporulation. Spores were harvested every 2 or 3 days. Data are from experiment 1.

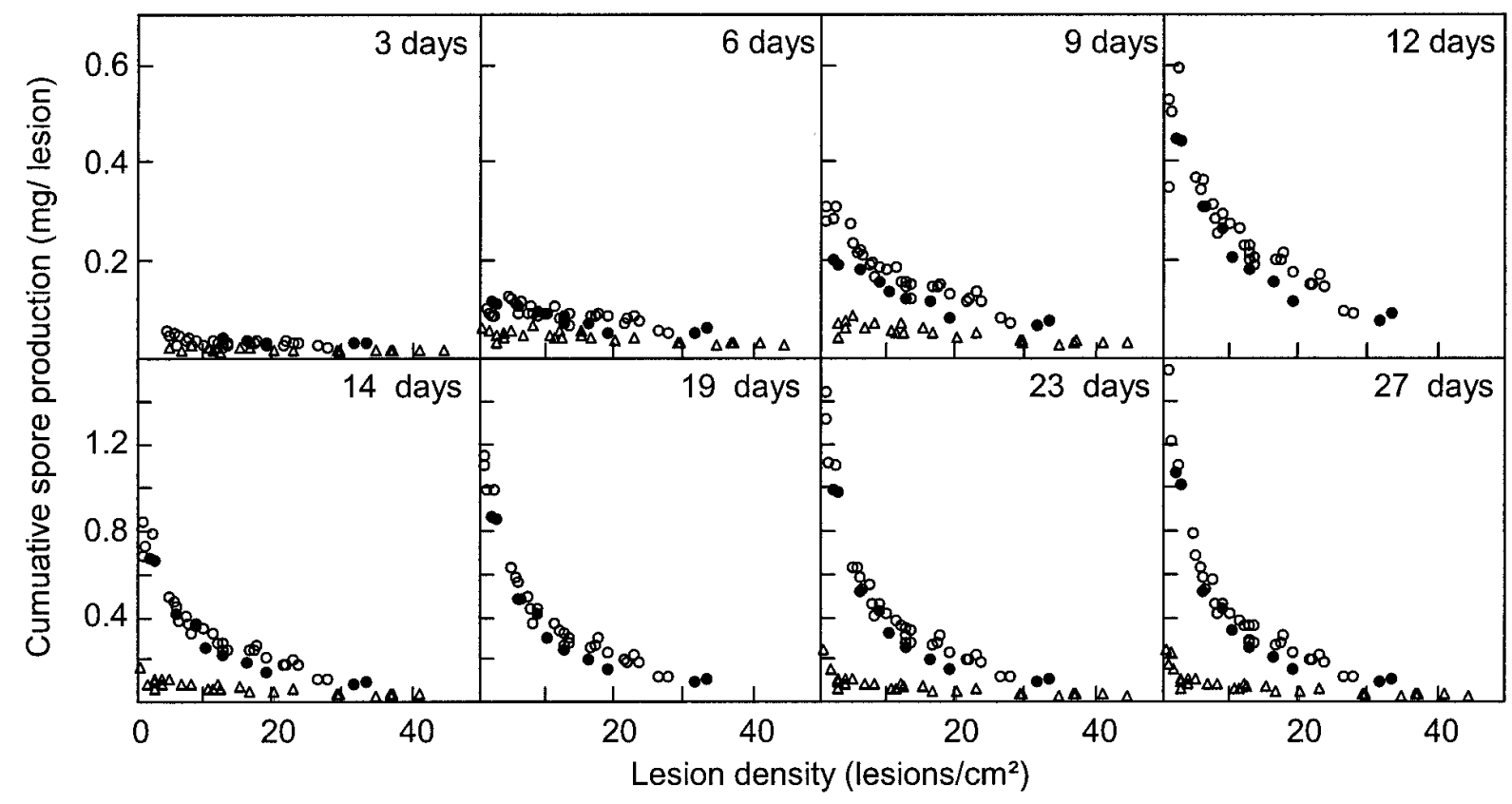

Fig. 2. Cumulative spore production per lesion for leaf rust (Puccinia triticina) on wheat (cv. Soisson), as a function of time and lesion density. Spore weight is in milligrams, lesion density is in lesion per square centimeter of leaf, and time is in days after onset of sporulation. Three sets of data are represented: experiment $1(O)$,experiment $2(\bullet)$, and experiment $3(\Delta)$. In experiment 3, the nitrogen content of the leaves was limiting. Ordinate scale is changed after day 12. 
production per lesion increased to a maximum and then decreased to zero at all lesion densities (Fig. 3). At low lesion densities, the length of the sporulation period and the maximum daily spore production both increased, and the date at which the maximum was reached was delayed. In experiment 1 , the maximum spore production per lesion decreased from $0.11 \mathrm{mg}$ per lesion per day at a lesion density of 0.6 lesion per $\mathrm{cm}^{2}$ to $0.01 \mathrm{mg}$ per lesion per day at a lesion density of 23.4 lesions per $\mathrm{cm}^{2}$. Spore production per lesion was maximal between 3 days after onset of sporulation, at the highest lesion densities ( $>20$ lesions per $\mathrm{cm}^{2}$ ), and 13 days after onset of sporulation, at the lowest lesion densities $(<1$ lesion per $\mathrm{cm}^{2}$ ). Sporulation lasted from 20 days at the highest lesion densities $\left(>20\right.$ lesions per $\mathrm{cm}^{2}$ ) to over 27 days at the lowest lesion densities $\left(<1\right.$ lesion per $\left.\mathrm{cm}^{2}\right)$.

Model for estimating spore production per lesion. The model's parameters were estimated with data from experiment 1 and 10 leaves in experiment 2 were used for validation. Cumulative spore production per lesion and lesion density were log-transformed (equation 1). After examination of the data distribution (Fig. 4), the data were split into two groups, one with lesion densities below 2 lesions per $\mathrm{cm}^{2}(0.7$ on the Ln scale) and the other with lesion densities above 2 lesions per $\mathrm{cm}^{2}$. Each data subset was analyzed separately.

For lesion densities below 2 lesions per $\mathrm{cm}^{2}$, parameter $b(t)$ in equation 1 was not significantly different from zero, suggesting that spore production per lesion was independent of lesion density. Before day 6 of sporulation, average spore production per lesion was lower in this data subset than for densities above 2 lesions per $\mathrm{cm}^{2}$, and this reversed after day 8 (Fig. 4). This suggests that spore production per lesion started slowly at very low lesion densities, but quite rapidly became higher than for greater densities.

For lesion densities greater than 2 lesions per $\mathrm{cm}^{2}$, cumulative spore production per lesion was correlated with lesion density according to equation 1 . The relationship between lesion density and cumulative spore production per lesion on day $3(t=3)$ was poorly explained by the model, but the model quality increased at day 6 and $R^{2}$ remained above 0.92 between day 9 and day 27 (Table 1). Parameters $a(t)$ and $b(t)$ of equation 1 were related to lesion age using equation 2 :

$$
\begin{aligned}
& a(t)=0.754-\exp (-0.174 \times t+1.981) \quad\left(R^{2}=1.00, P=3 \mathrm{E}-5\right) \\
& b(t)=0.749-\exp (-0.144 \times t+0.153) \quad\left(R^{2}=0.99, P=2 \mathrm{E}-4\right)
\end{aligned}
$$

Cumulative spore production per lesion was then related to lesion density and lesion age by equation 4 . The cumulative spore production per lesion for each collection date $(t=3,6,9,12,15$, 19,23 , and 27) estimated with equation 4 was plotted against the corresponding measured values from experiment 1 (Fig. 5). The model fitted the data correctly $\left(R^{2}=0.98, P=2 \mathrm{E}-177\right)$ and the residue distribution showed no bias. Equation 4 was validated with data from experiment 2 (Fig. 5), which showed a good fit for the model $\left(R^{2}=0.98, P=9 \mathrm{E}-67\right)$.

Lesion size assessment. A subset of 22 leaves in experiment 2 was used to measure individual lesion size. Lesions were larger for lower lesion densities from day 4 after onset of sporulation, and this difference increased with time (Fig. 6). Lesions stopped growing around day 11 at the highest densities and around day 18

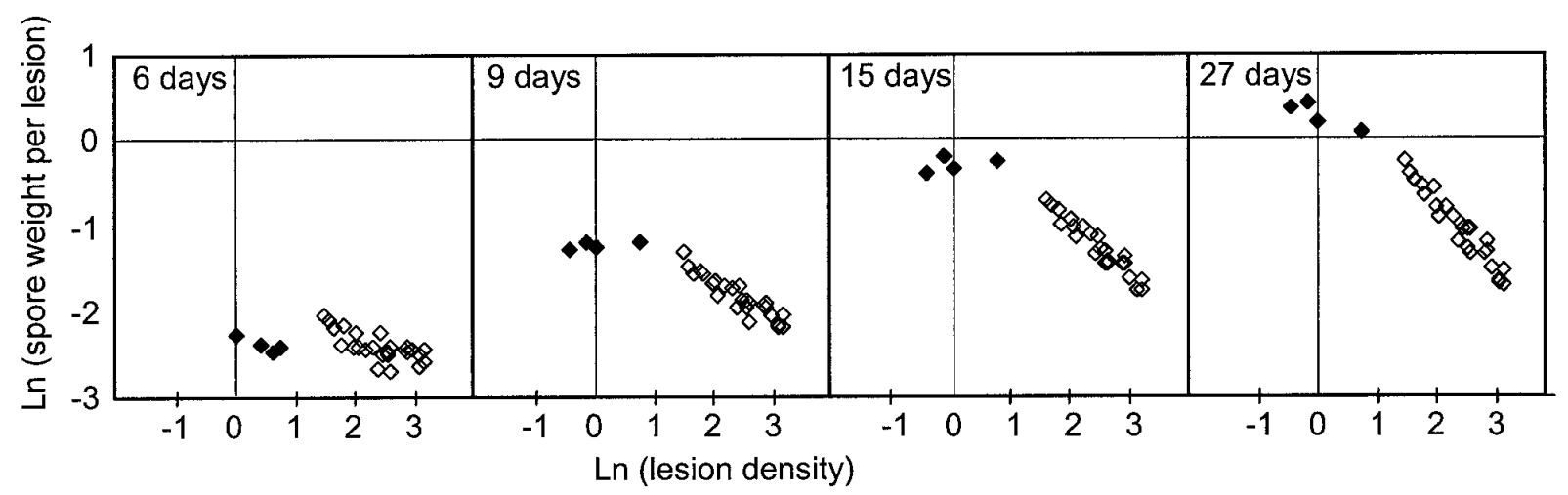

Fig. 4. Cumulative spore production per lesion for leaf rust (Puccinia triticina) on wheat as a function of lesion density, after a double log-transformation, for different dates. Spore weight is in milligrams, lesion density is in lesions per square centimeter of leaf, and time is in days after onset of sporulation. Two different models were used to fit the data below $(\diamond)$ and above $(\diamond) 2$ lesions per $\mathrm{cm}^{2}(0.7$ on the logarithmic [Ln] scale). Data are from experiment 1.

TABLE 1. Statistics for the cumulative spore production model (equation 1) and lesion size model (equation 6) for leaf rust (Puccinia triticina) on wheat

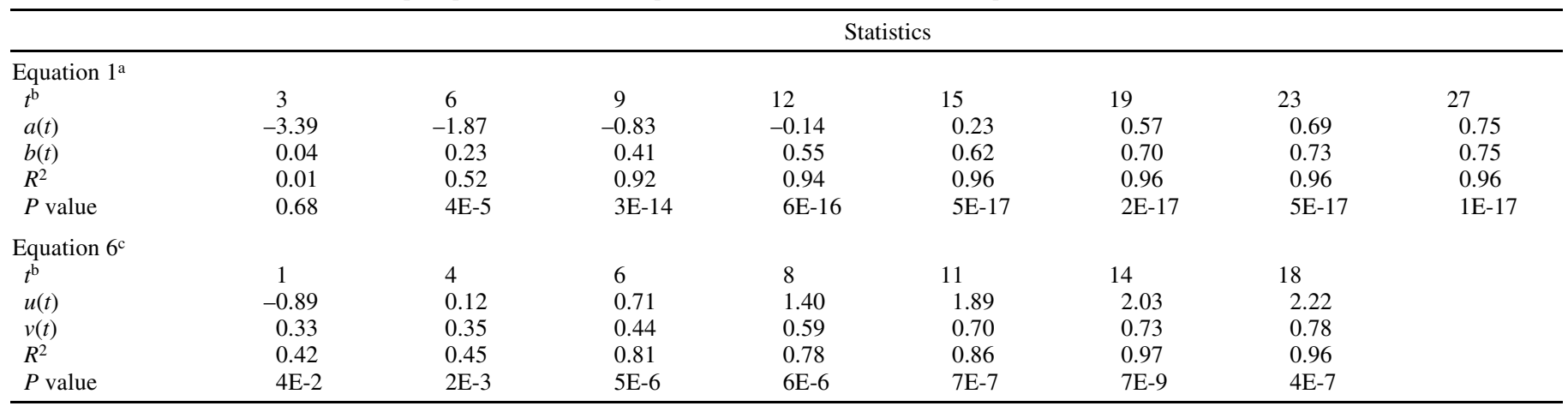

${ }^{\mathrm{a}}$ Equation $1: \ln \left[Y_{t}(d)\right]=a_{t}-b_{t} \times \ln (d), d=$ lesion density.

b $t=$ time, in days after onset of sporulation.

${ }^{\mathrm{c}}$ Equation 6: $\ln \left[S_{t}(d)\right]=u_{t}-v_{t} \times \ln (d), d=$ lesion density. 
at the lowest densities. The maximal lesion size on day 18 was $4.7 \mathrm{~mm}^{2}$ for a density of 0.3 lesion per $\mathrm{cm}^{2}$ and the minimal lesion size was $0.7 \mathrm{~mm}^{2}$ for densities of $>20$ lesions per $\mathrm{cm}^{2}$. Visually, the relationship between lesion size and lesion density was similar to that between cumulative spore production per lesion and lesion density.

Lesion size model. Data for lesion densities above and below 2 lesions per $\mathrm{cm}^{2}$ were analyzed separately. For lesion densities greater than 2 lesions per $\mathrm{cm}^{2}$, the sporulating area was related to lesion density using equation 6 . The relationship between lesion density and sporulating area was correctly described by the model

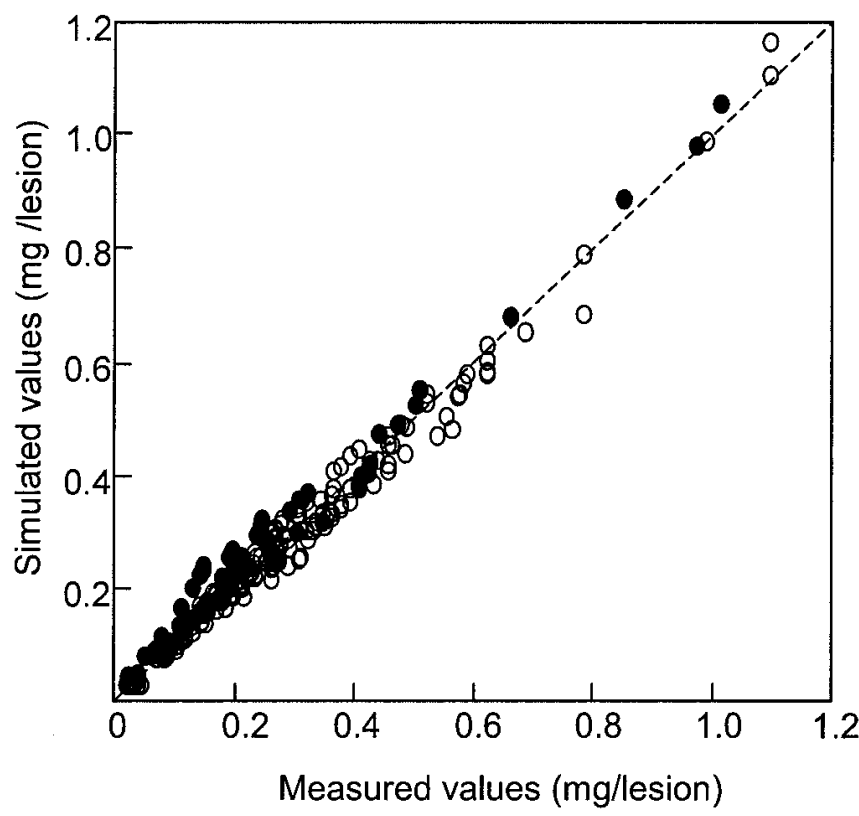

Fig. 5. Comparison of simulated and measured data for cumulative spore production per lesion of leaf rust (Puccinia triticina) on wheat (milligrams per lesion) for each leaf and collection date. Dotted line: $y=x . \bigcirc=$ data from experiment $1, \bullet=$ data from experiment 2 , for validation.
(Table 1). Parameters $u(t)$ and $v(t)$ in equation 6 were related to lesion age according to equation 7 :

$$
\begin{array}{ll}
u(t)=2.216-\exp (-0.254 \times t+1.817) & \left(R^{2}=0.99, P=5 \mathrm{E}-4\right) \\
v(t)=0.781-\exp (-0.230 \times t+0.162) & \left(R^{2}=0.99, P=6 \mathrm{E}-4\right)
\end{array}
$$

Sporulating area was related to lesion density and lesion age using equation 8 . Sporulating areas estimated by equation 8 for collection dates $t=4,6,8,11,14$, and 18 were plotted against the corresponding experimental values. The model explained the data well $\left(R^{2}=0.91, P=1 \mathrm{E}-45\right)$. The residue distribution showed no bias.

Uredospore production per square millimeter of sporulating area. Daily spore production per square millimeter of sporulating area was modeled by dividing the estimated spore production per lesion per day (equation 5, Fig. 7B) by the estimated lesion size (equation 8, Fig. 7A). The strong effect of density on spore production disappeared when spore production was related to the sporulating area (Fig. 7C). The overall spore production for the whole sporulation period ranged from $0.43 \mathrm{mg} / \mathrm{mm}^{2}$ of sporulating area at 3 lesions per $\mathrm{cm}^{2}$ to $0.35 \mathrm{mg} / \mathrm{mm}^{2}$ of sporulating area at 30 lesions per $\mathrm{cm}^{2}$. Daily spore production per square millimeter of sporulating area increased to a maximum and then decreased toward zero (Fig. 7C). The model predicted a maximum value around $0.034 \mathrm{mg} / \mathrm{mm}^{2}$ for spore production, which can be considered independent of lesion density. This maximum was reached 4 days after onset of sporulation for all lesion densities. Over $80 \%$ of the spores were produced before day 15 of sporulation, regardless of lesion density. However, there was a slight density effect after the maximum was reached, with lower spore production and a shorter sporulation period for greater lesion densities (Fig. 7C).

$\mathbf{N}$ and $\mathbf{C}$ contents of spores and primary leaves. The carbon and nitrogen levels (percent) of the spores were constant and did not depend on lesion density (Fig. 8). Spores contained $49.9 \%$ $(\sigma=0.5), 50.0 \%(\sigma=1.3)$, and $48.9 \%(\sigma=0.9)$ carbon in experiments 1,2 , and 3 , respectively. The carbon levels of primary leaves before inoculation were similar in experiments 1 and 3. Primary leaves contained $40.2 \%(\sigma=0.9)$ and $39.8 \%(\sigma=0.6)$ carbon in experiments 1 and 3, respectively.

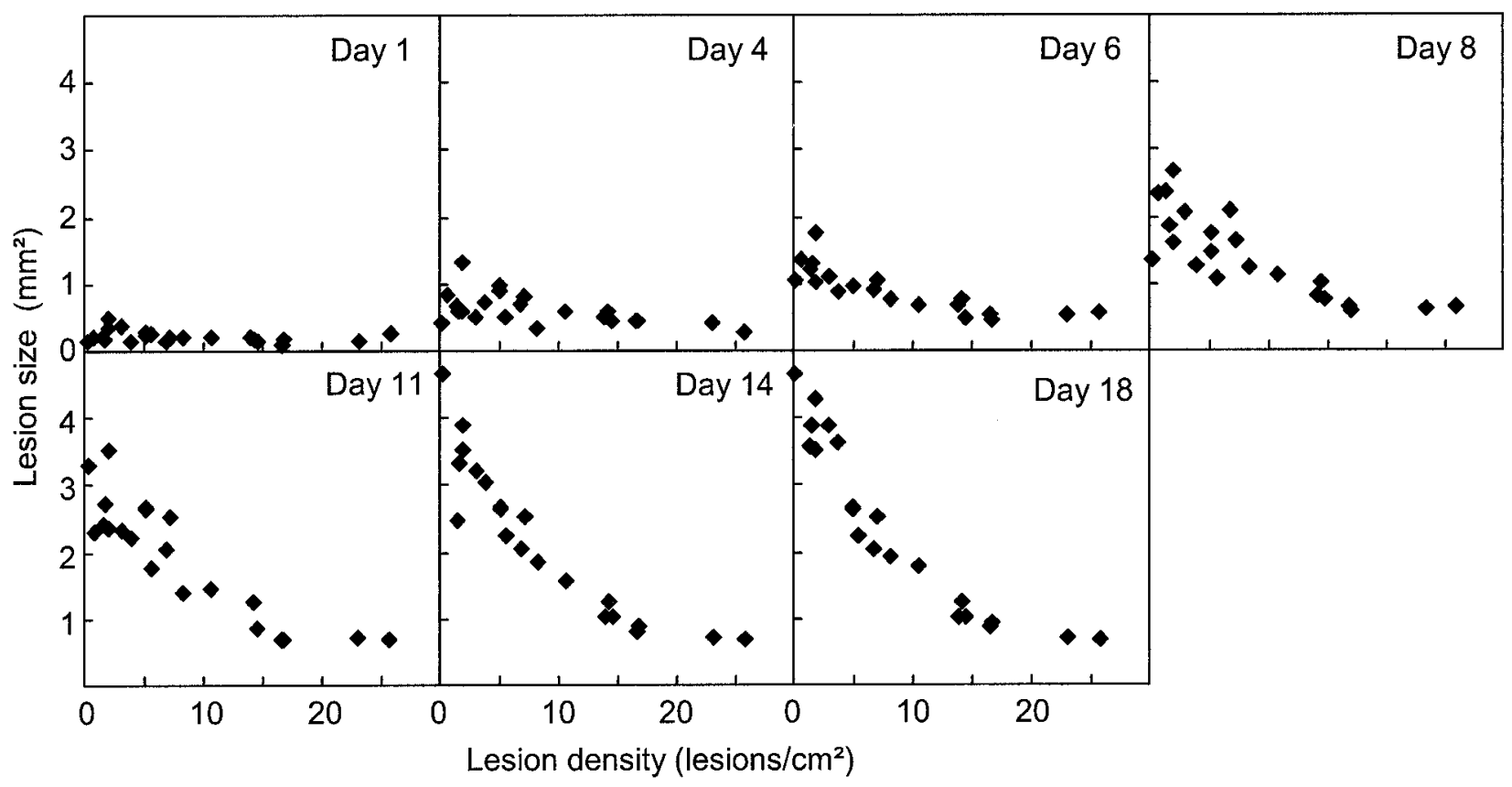

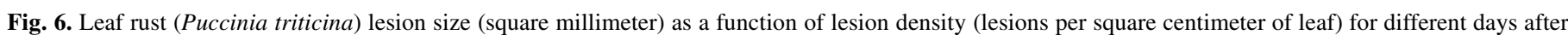
onset of sporulation. Data set is from experiment 2. Lesion size is defined as the sporulating area. 
The nitrogen levels (percent) of primary leaves before inoculation differed greatly in experiments 1 and 3: leaves contained $6.4 \%(\sigma=0.3) \mathrm{N}$ in experiment 1 and only $2.8 \%(\sigma=0.4) \mathrm{N}$ in experiment 3. In contrast, spores contained $4 \%(\sigma=0.05) \mathrm{N}$ in experiments 1 and 2 , and $3.4 \%(\sigma=0.1) \mathrm{N}$ in experiment 3 . The $\mathrm{N} / \mathrm{C}$ ratios of the leaves differed in experiments $1(\mathrm{~N} / \mathrm{C}=16)$ and $3(\mathrm{~N} / \mathrm{C}=7.1)$, but those for the spores were almost similar $(\mathrm{N} / \mathrm{C}=$ 7.9 in experiments 1 and $2, \mathrm{~N} / \mathrm{C}=7$ in experiment 3 ).

\section{DISCUSSION}

Our study confirmed that uredospore production results in a significant loss of biomass in diseased crops. Thus, uredospore production has to be introduced as a damage function in diseased plant models. The weight of the spores $(20 \mathrm{mg})$ produced by a primary leaf exceeded the mean dry weight of the leaf $(13 \mathrm{mg})$, which is consistent with the findings of Mehta and Zadoks (13). For the dynamics of uredospores production, the pattern of leaf rust sporulation, expressed in milligram of spores per lesion per day was similar to those obtained by other authors, expressed as the number of spores per lesion per day $(13,14)$. The weight of spores produced by a single lesion was greatly reduced at high lesion density. A similar density effect on spore production has been reported for several rust fungi $(1,9,15,20)$. Our data suggest that the density effect on spore production shows a threshold at around 2 lesions per $\mathrm{cm}^{2}$ below which sporulation is independent of density. Below this threshold, spore production per lesion started slowly, but increased rapidly after 7 days of sporulation. This could be due to the rings of secondary lesions that appeared 1 week after onset of sporulation at the lowest lesion densities and suggests that the secondary lesions increased the host tissue area exploited by the fungus.

Our results showed that increasing lesion density also greatly reduced lesion size, but spore production became independent of lesion density when expressed as spores per square millimeter of sporulating area instead of spores per lesion. Other authors assumed that the density effect on spore production should result from competition between adjacent uredia, reducing the sporulation capacity of individual uredia $(1,9,15,20)$. According to our model, most of the effect of density on spore production per lesion could be accounted for by lesion size. A residual density effect remained, however, because the total weight of spores produced
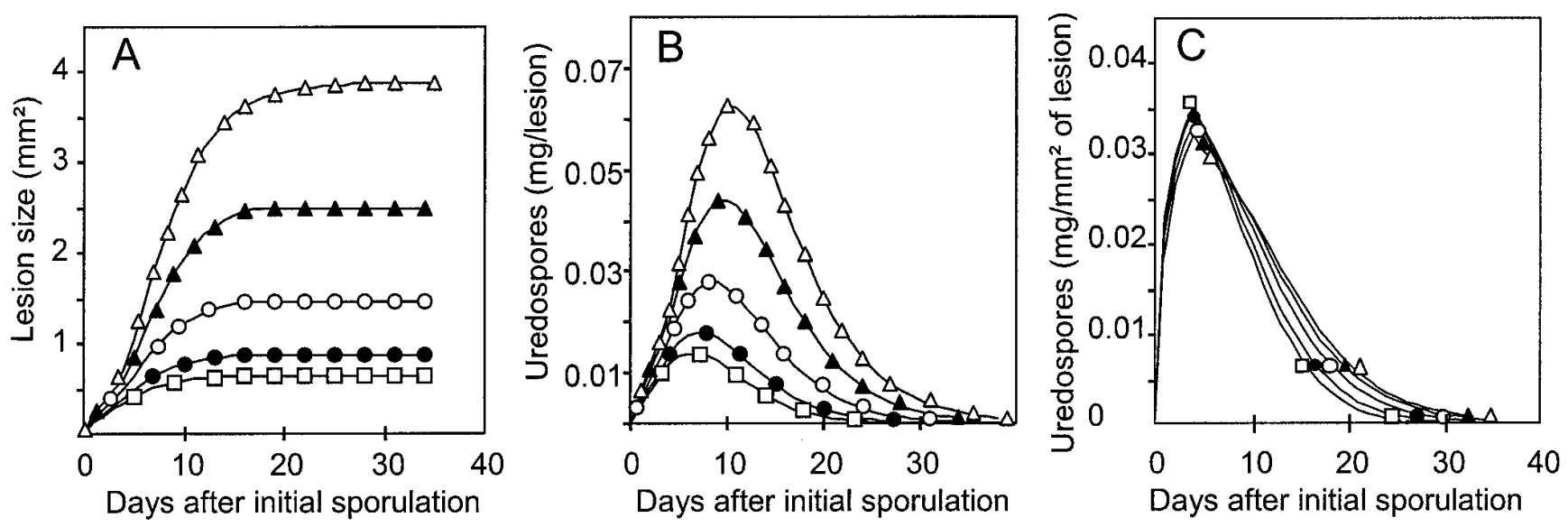

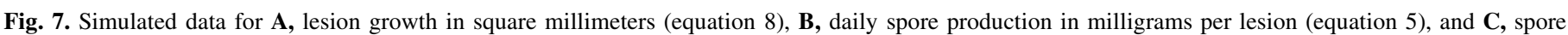

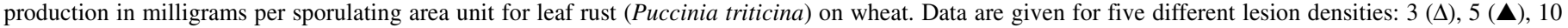
(○), $20(\bullet)$, and $30(\square)$ lesions per $\mathrm{cm}^{2}$.
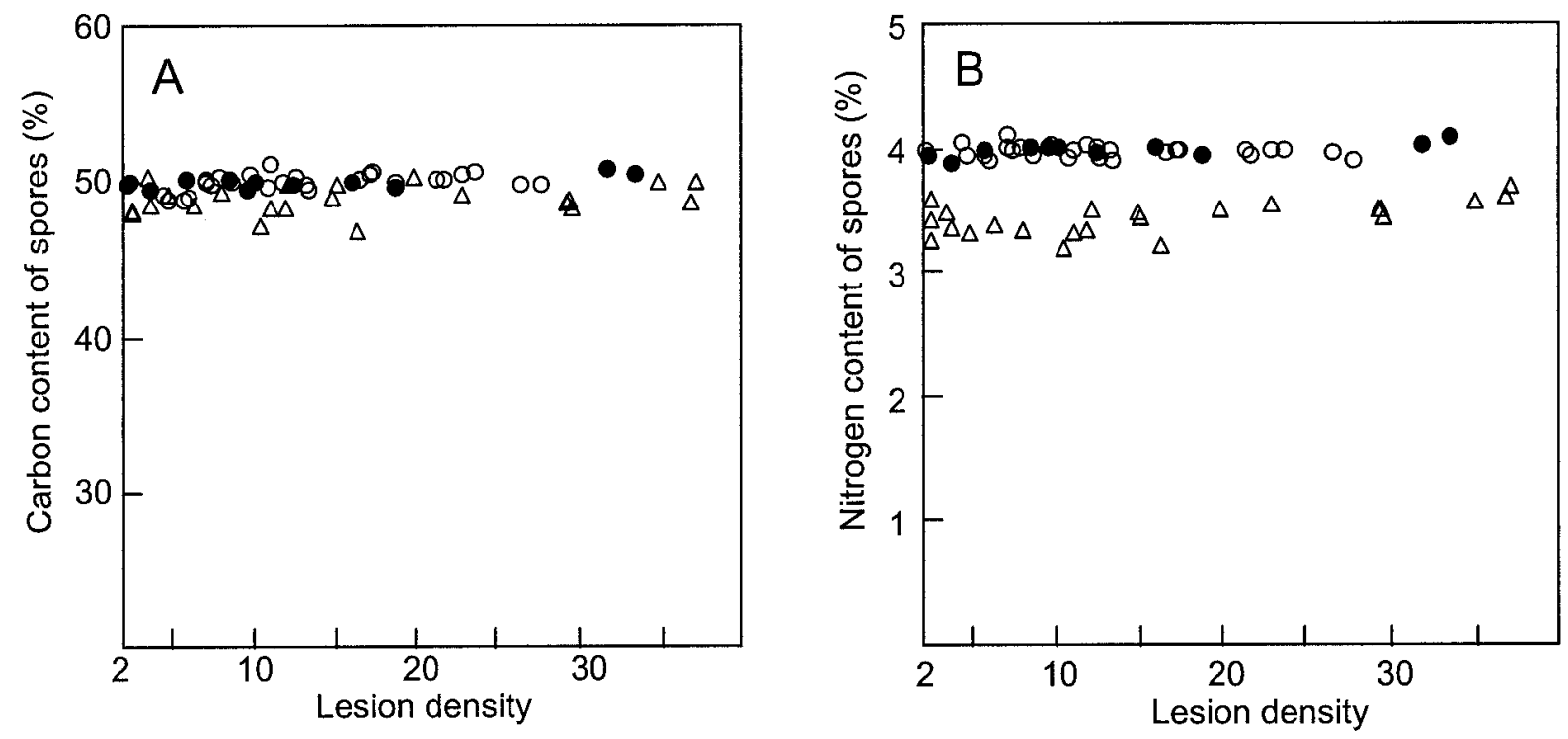

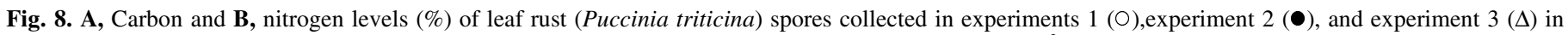

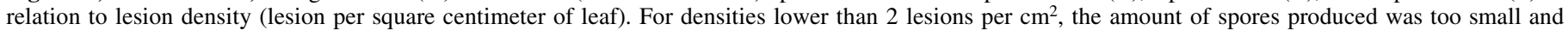
data are not available. In experiment 3 , the nitrogen content of the leaves was limiting. 
per square millimeter of sporulating area was slightly lower for high lesion densities than for low lesion densities. This residual effect resulted from a slightly faster decrease in spore production and a shorter sporulation period at high lesion densities. The fast decrease in spore production per square millimeter of sporulating area for all lesion densities suggest that there is a limitation in leaf nutrients available for the fungus.

The large difference in spore production in experiments 1 and 3 suggests that the nitrogen content of the leaves significantly affects spore production. Although the experimental design was the same for all experiments, seed germination and first leaf development was not optimal in experiment 3 . This resulted in the leaves having a low nitrogen content and in spore production being more than $70 \%$ lower at all lesion densities than in experiments 1 and 2. Several authors have shown that the nitrogen content of the leaves has a great influence on disease development $(8,18)$.

In the experiments, the carbon and nitrogen levels of the spores remained constant at all lesion densities. The spores contained about $50 \%$ carbon and between 3.4 and $4 \%$ nitrogen. Because the $\mathrm{C}$ and $\mathrm{N}$ contents of the spores were independent of lesion density, losses of carbon and nitrogen from infected leaves can be directly estimated from the dry weight of spores. In experiments 1 and 2, for lesion densities greater than 15, the spore production per square centimeter of leaf was maximal (Fig. 1) and the total amount of carbon and nitrogen exported reached 2.2 and $0.18 \mathrm{mg}$ per $\mathrm{cm}^{2}$ of leaf, respectively. In experiment 3 , exported carbon and nitrogen were reduced by more than $70 \%$, corresponding to $0.5 \mathrm{mg}$ of $\mathrm{C}$ and $0.04 \mathrm{mg}$ of $\mathrm{N}$ per $\mathrm{cm}^{2}$ of leaf. As well, carbon and nitrogen exported per square millimeter of sporulating area can be estimated from spore production per square millimeter of sporulating area. According to our model, exported carbon per square millimeter of sporulating area ranged from 0.21 to $0.18 \mathrm{mg}$ and exported nitrogen per square millimeter of sporulating area ranged from 0.017 to $0.014 \mathrm{mg}$ when lesion density was increased from 3 to 30 lesions per $\mathrm{cm}^{2}$.

The weight of spores produced in experiment 3 was strongly reduced relative to experiment 1 , but the nitrogen content of the spores remained almost constant, suggesting that the nitrogen content is strongly regulated in the spores. The difference in the nitrogen levels of the spores ( 4 and 3.4\%) in experiments 1 and 3 was much smaller than that of the leaves (6.4 and 2.8\%). In experiment 1 , the nitrogen level of the leaves was probably not limiting for spore production. In experiment 3 , the spores contained more nitrogen $(3.4 \%)$ than the leaves $(2.8 \%)$, which suggests a priority for nitrogen allocation to the spores rather than to the plant. In field epidemics, leaf rust should then affect yield quality by diverting nitrogen fluxes from infected leaves to spikes during the grain filling period.

These experiments were conducted under environmental conditions that were optimal for brown rust, and spore production was measured on primary leaves. As in other studies (13), secondary leaves were cut for facilitating measurements. It is difficult to say whether this affected spore production or not. More seed assimilates were available for the primary leaf but the global photosynthesis of the plant was reduced. Such measurements are technically impossible under field conditions. However, we assume that the pattern of spore production per unit of sporulating area on adult plants is also constant over time and independent of lesion density when nitrogen is not limiting. The nitrogen content of the host leaves may vary under field conditions, which should influence the amount of spores produced by the pathogen.
The sporulating area should be a suitable variable for simulating the effect of brown rust on wheat because brown rust spore production per sporulating area unit is independent of lesion density and because the main effect of brown rust on photosynthesis is directly related to the diseased surface area (17). Lastly, the nitrogen and carbon content of spores can be used to estimate amounts of nitrogen and carbon exported by the pathogen and its consequences for yield quality.

\section{LITERATURE CITED}

1. Baart, P. G. J., Parlevliet, J. E., and Limburg, H. 1991. Effects of infection density on the size of barley and wheat leaf rust colonies before and on the size of uredia after the start of sporulation. J. Phytopathol. 131: 59-64.

2. Bassanezi, R. B., Amorim, L., Bergamin Filho, Hau, B., and Berger, R. D. 2001. Accounting for photosynthetic efficiency of bean leaves with rust, angular spot and anthracnose to assess crop damage. Plant Pathol. 50:443-452.

3. Bastiaans, L. 1993. Effects of leaf blast on growth and production of a rice crop. 2. Analysis of the reduction in dry matter production, using two models with different complexity. Neth. J. Plant Pathol. 99:19-28.

4. Dumas, J. B. A. 1831. Procédés de l'analyse organique. Ann. Chim. Phys. 247:198-213.

5. Eyal, Z., Clifford, B. C., and Caldwell, R. M. 1968. A settling tower for quantitative inoculation of leaf blades of mature small grain plants with urediospores. Phytopathology 58:530-531.

6. Gary, G., Jeuffroy, M. H., Ney, B., and Tivoli, B. 1998. Effects of Aschochyta blight on the decrease in photosynthesizing leaf area and the reduction of photosynthetic efficiency by green leaf area of dried-pea. Plant Pathol. 47:473-479.

7. Grath, M. T., and Pennypacker, S. P. 1990. Alteration of physiological processes in wheat flag leaves caused by stem rust and leaf rust. Phytopathology 80:677-685.

8. Leitch, M. H., and Jenkins, P. D. 1995. Influence of nitrogen on the development of Septoria epidemics in winter wheat. J. Agric. Sci. 124:361368.

9. Leonard, K. J. 1969. Factors affecting rates of stem rust increase in mixed plantings of susceptible and resistant oat varieties. Phytopathology 59:1845-1850.

10. Lim, L. G., and Gaunt, R. E. 1981. Leaf area as a factor in disease assessment. J. Agric. Sci. 97:481-483

11. Madden, L. V., and Nutter, F. W. 1995. Modeling crop losses at the field scale. Can. J. Plant Pathol. 17:124-137.

12. Madeira, A. C., Clark, J. A., and Rossal, S. 1994. Growth and light interception in field bean (Vicia faba) infected by Ascochyta fabae. J. Agric. Sci. 123:225-232.

13. Mehta, Y. R., and Zadoks, J. C. 1970. Uredospore production and sporulation period of Puccinia recondita f. sp. triticina on primary leaves of wheat. Neth. J. Plant Pathol. 76:267-276.

14. Sache, I. 1997. Effect of density and age of lesions on sporulation capacity and infection efficiency in wheat leaf rust. Plant Pathol. 46:581589.

15. Sache, I., and De Vallaveille-Pope, C. 1993. Comparison of the wheat brown and yellow rusts for monocyclic sporulation and infection processes, and their polycyclic consequences. J. Phytopathol. 138:55-65.

16. Savary, S., De Jong, P. D., Rabbinge, R., and Zadoks, J. C. 1990. Dynamic simulation of groundnut rust: A preliminary model. Agric. Syst. 32:113-141.

17. Shtienberg, D. 1992. Effects of foliar diseases on gas exchange processes: A comparative study. Phytopathology 82:760-764.

18. Snoeijers, S., Pérez-Garcia, A., Joosten, M., and De Witt, P. 2000. The effect of nitrogen on disease development and gene expression in bacterial and fungal plant pathogens. Eur. J. Plant Pathol. 106:493-506.

19. Van Roermund, H. J. W., and Spitters, C. J. T. 1990. Simulation of yield reduction by leaf rust in winter wheat, applied to the analysis of genetic variation in partial resistance. Neth. J. Plant Pathol. 96:17-28.

20. Yarwood, C. E. 1961. Uredospore production by Uromyces phaseoli. Phytopathology 51:22-27. 